\title{
SEMBLANZA DEL HISTORIAL CIENTÍFICO DEL PROF. Dr. D. ANTONIO HIGUERAS ARNAL
}

\author{
$\mathrm{M}^{\mathrm{a}}$ Carmen Faus Pujol \\ Departamento de Geografía y Ordenación del Territorio. Facultad de Filosofía y Letras. \\ Universidad de Zaragoza. Pedro Cerbuna, 12. 5000 Zaragoza. Correo Electrónico: \\ mcfaus@posta.unizar.es
}

\section{Introducción}

El Consejo de Redacción de Geographicalia me encargó, hace ya algunos meses, que hiciera una breve semblanza o bosquejo del historial científico del profesor Higueras, Catedrático Emérito de la Universidad de Zaragoza. No ha sido tarea fácil. Mas de cincuenta años de actividad docente e investigadora no caben en unas pocas páginas: en tan corto espacio es imposible resumir las múltiples facetas de la personalidad docente, científica y humana del profesor Higueras, geógrafo, científico, profesor y maestro, con una gran pasión por la enseñanza y la investigación geográfica. Él mismo cuenta que llegó a la Geografía de forma casual. Recién terminados los estudios de magisterio, que simultaneó con los de bachillerato, y con solo 18 años, tuvo a su cargo una escuela de enseñanza primaria. Su vocación por la enseñanza le inclinaba hacia la pedagogía, por lo que se matriculó en los cursos comunes de la Licenciatura de Filosofía y Letras de la Universidad de Zaragoza, paso previo para estudiar en Madrid la especialidad de pedagogía. Recuerda que no era fácil atender una escuela con más de cincuenta niños y estudiar al mismo tiempo. Por eso se examinaba solamente de las asignaturas que había estudiado a fondo y consideraba que estaba en condiciones de aprobar. Aun así, cuenta que se llevó más de un chasco y recuerda con humor que en algún caso se creó una "relación afectiva" entre profesor y alumno por la frecuencia de "encuentros académicos Junio-Septiembre-Junio-Septiembre", que tuvieron en aquellos primeros años, siempre para hablar de la misma materia.

En uno de esos cursos "penitenciales", como gusta recordar, tuvo que incorporarse a las milicias universitarias para realizar el servicio militar y solicitó examen extraordinario con anterioridad a la fecha de la convocatoria oficial, de una asignatura que llevaba bien preparada: se trataba de la Geografía General de segundo. El día del exa- 
men, que fue oral, el profesor, un joven catedrático -D. José Manuel Casas Torres- le rogó que saliera al pasillo a buscar a alguien que quisiese presenciar el examen, ya que, por ser alumno libre, el examen tenía que ser público. Aunque habló con unos y otros, nadie quería ser testigo del examen. El profesor Casas llevaba fama de ser muy duro (lo cual no era cierto) y a todos les daba lástima presenciar el suspenso de un alumno.

Después de mucho insistir y rogar, tan solo accedió a acompañarle, Alejandro, un buen amigo y compañero que luego profesó como escolapio y ocupó importantes cargos de gobierno en la orden. El examen, según cuenta el profesor Higueras, fue como cualquier otro: "Dígame Ud. esto; hábleme de aquello...", y así, durante casi una hora de preguntas y respuestas. Al final, después del consabido "puede Ud. retirarse", se formó en el pasillo el corrillo de siempre, donde se hacían comentarios sobre el examen mientras se esperaba a que saliese la nota. Como tardaba en salir y aquella misma noche tenía que tomar el tren para el campamento, el recién examinado, acompañado por su amigo Alejandro, fue a preguntarle al profesor Casas por la nota. La respuesta fue insospechada: Sobresaliente y Matrícula de Honor. Nadie en el pasillo salía de su asombro. El profesor Higueras, después de lo que habían dicho sus compañeros antes del examen, tampoco. Tanto era así, que volvió al despacho del Profesor y le preguntó: "¿esta nota me la ha dado Ud. porque sí, o me la he ganado?", La respuesta la sé pero no voy a descubrirla aquí, porque el profesor Higueras la guarda para sus "memorias". Entonces se inició una relación de amistad, colaboración, lealtad y afecto entre maestro y discípulo que todavía dura.

La lealtad hacia sus maestros y alumnos ha sido una constante en el quehacer del Profesor Higueras. Muchas veces le he oido comentar que "la labor de un profesor es que sus alumnos luzcan, porque para lucirse él, tiene los congresos y las publica-

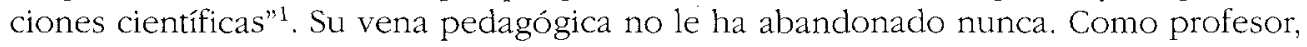
intentaba hacer fácil lo difícil. Solía decir en clase que "cuando a un profesor no se le entiende es por dos cosas: o porque habla bajo, o porque él tampoco lo ha entendido, y así es imposible que se le entienda, aunque hable alto". Compartiendo trabajo y estudio, finaliza la licenciatura de Filosofía y Letras y se orienta hacia la Geografia, una disciplina a la que ha dedicado toda su actividad docente e investigadora, incluso cuando ha irrumpido en otros campos científicos, como la Edafología.

\section{Los primeros trabajos y su interés por la Edafología}

Tras licenciarse en 1955, comienza su formación edafológica dedicando especial atención al estudio de los suelos, por la importancia que estos tienen en la forma-

1 Nota de la redacción: los términos y frases entrecomillados en el texto corresponden a conceptos e ideas utilizados o expresados por el Dr. Higueras en sus clases e investigaciones, y no constituyen propiamente citas bibliográficas. 
ción de los paisajes naturales. Su formación en Edafología no fue casual. En aquellos años el Departamento de Geografía de Zaragoza, perteneciente al Instituto Juan Sebastián Elcano del C.S.I.C., propiciaba la formación de los geógrafos en áreas específicas de la Geografía, de manera que dominasen un determinado campo "científico" sin dejar de ser geógrafos. El proyecto de formación de geógrafos en áreas afines a la Geografía no era una improvisación. Por aquel tiempo, dentro de la Licenciatura en Geografía e Historia de la Facultad de Filosofía y Letras, los alumnos podían optar entre especializarse en Geografía o en Historia. Según la orientación elegida, en los planes de estudio pesaba más la Geografía o la Historia. Así, los alumnos de la "Orientación en Geografía" de nuestra Universidad, estudiaban algunas asignaturas de las carreras de Derecho y de Ciencias en las respectivas facultades, especialmente derecho agrario y matemáticas, por la importancia que ya entonces se daba al medio rural y a las técnicas de análisis cuantitativo. Esta experiencia no fue del todo satisfactoria. Tanto los profesores de Derecho como los de Ciencias explicaban para sus alumnos, que tenían una formación diferente a la de los alumnos de Geografía. Por eso, sin abandonar la idea principal, se vio que era necesario formar geógrafos en las diferentes materias "periféricas" de la Geografía. Al Profesor Higueras le correspondió formarse en dos materias: "Fotointerpretación aérea" y "Edafología".

En aquellos años de mitad del siglo XX, la fotointerpretación desempeñaba un papel semejante al que hoy tiene la teledetección. El Profesor Higueras adquirió la titulación en el Institut Geographique National de Saint Mande, París, siendo probablemente el primer geógrafo español que trabajó científicamente con las técnicas de fotointerpretación, muy deficientes, por cierto, comparadas con lo que se hace hoy. En 1959 aparece en Geographica, revista del Departamento de Geografía del C.S.I.C. en Zaragoza, un primer artículo sobre fotointerpretación titulado Sobre la fotografía aérea como instrumento de trabajo en Geografia ${ }^{2}$. Aunque el Profesor Higueras no llegó a explicar esta materia, porque se trasladó a Madrid, la fotointerpretación, de la mano entonces del profesor Mensua, fue una de las asignaturas más atractivas del Departamento durante decenios, y sirvió para realizar multitud de trabajos de geomorfología, aprovechamiento del suelo, etc.

Donde el Profesor Higueras destacó como experto fue en edafología. Becario del C.S.I.C en el Instituto de Edafología durante 1956, se formó en Reinbeck (Hamburgo) de la mano del profesor Kubiena, sin duda la mayor autoridad mundial del momento en suelos naturales, en el Bundesforscbungsanstalt für Forts und Holzwirtschaft. De regreso a España desarrolla una importante labor científica en el Instituto de Edafología, como investigador de carrera. De está época cabe reseñar algunos de sus trabajos realizados individualmente o en equipo, como Estudio agrobiológico y mapa

2 Ésta y las demás referencias de trabajos científicos aparecen listadas cronológicamente al final del texto. 
de suelos del valle del río Saja y el Mapa de suelos de la provincia de Santander, publicados en 1958. Aunque estudios de edafología, se percibe en ellos la vocación geográfica de sụ autor, que ha mantenido siempre. Así, en el artículo Die Stellung der Bodenkunde in der Geographischen Wissenschaft, publicado en 1958 en la revista Die Erde, que se editaba en Berlín Oriental, defiende la importancia del suelo en la ciencia geográfica. El artículo fue muy comentado porque seguía la tradición de los grandes geógrafos alemanes, como Troll, Lautensach, Lauer y otros. Preocupado por la difusión de las nuevas conquistas de la ciencia del suelo, da a conocer en reuniones científicas internacionales los resultados de sus investigaciones en equipo, mediante comunicaciones como Micromorphologic and Chemical Study of Humus Formation from Different Vegetal Species, en el $7^{\circ}$ Congreso Internacional de Ciencias del Suelo celebrado en Madison (Wisconsin, EE.UU) en 1960; o La cartografía de suelos en España, en el XX Congreso Geográfico Internacional de 1964 celebrado en el Reino Unido. En la primera de estas comunicaciones llama la atención sobre la conveniencia de realizar repoblaciones forestales con especies adaptadas a las condiciones ecológicas del lugar. La segunda, en cambio, es una actualización de los trabajos de cartografía de suelos realizados hasta entonces en España.

En la misma línea de estudios edafológicos se hallan el Estudio de los suelos en los nuevos regadios del Valle Medio del Ebro realizado con la beca March en 1964 y la Infuencia de la vegetación en los procesos de bumificación de suelos forestales pirenaicos en colaboración con D. José M. Albareda y Francisco Velasco, que se presentó al Congreso de Estudios Pirenaicos de Pau-Lourdes, 1962. Mediante análisis químicos y micromorfológicos (la especialidad del profesor Higueras) de muestras de suelos consiguen determinar la evolución del humus en función de las condiciones de temperatura y humedad. Ello les permite comprobar la velocidad de mineralización del suelo, la actividad biológica del humus y su variación a lo largo del año. Se trata de investigaciones de base realizadas para hacer efectivos los trabajos de reforestación.

El Pirineo, especialmente el Pirineo aragonés, es objeto de muchos estudios de suelos que realiza en el Instituto de Edafología de Madrid. Entre ellos destaca la Caracterización mineralógica y micromorfológica de algunos suelos calizos del Pirineo realizado según las técnicas del profesor Kubiena en colaboración con Benayas, y publicado en Anales de Edafología. Trabajo semejante, aunque en otro ámbito geográfico, es el estudio de Los suelos naturales de las islas de Sta. Maria y San Miguel (Azores), que se publicó en Açoreana en 1962. Un ejemplo del interés del profesor Higueras por las nuevas metodologías es el trabajo de difusión titulado: Methoden und Einrichtungen der Herstellung von Boden Dünnschliffen in der Sektion für Micromorphometrische Boden Analyse (Stuttgart, 1967) referido a análisis micromorfológico de los suelos. 


\section{De los estudios sobre regadíos al enfoque regional}

Aunque en sus comienzos el Profesor Higueras fue geógrafo esencialmente físico, la formación que recibían los geógrafos en aquel entonces abarcaba todo el contenido de la Geografía. Todavía hoy sorprende que geógrafos tan específicamente físicos como Tricart, y Birot, por ejemplo, escribieran excelentes manuales de Geografía Humana. Por eso, entre sus trabajos abundan los de contenido regional o en relación con las actividades humanas, de los cuales entresacamos algunos. De hecho su primera publicación, La geodemografía de la provincia de Logroño (1956), pone de manifiesto su formación humanística y la importancia que concede a los estudios de población en Geografía, los cuales constituirán su principal centro de interés en los últimos treinta años. No se trata de una simple enumeración estadística de los elementos demográficos de la provincia, sino que introduce comentarios que ayudan a comprender su personalidad geográfica y las causas de la evolución negativa de la población a lo largo de la primera mitad del siglo XX (1900-1950). Aunque el periodo estudiado abarca medio siglo, el proceso de despoblación se había iniciado mucho antes, coincidiendo con la decadencia de La Mesta. En el texto introduce conceptos y métodos para el estudio y representación cartográfica de la población, especialmente las técnicas de representación de Sten de Geer que en aquel momento eran una novedad y habían sido introducidas en España por el profesor Casas Torres.

Siempre con la preocupación de encontrar nuevos resquicios por donde acometer el análisis de los hechos geográficos, se propone estudiar la estructura agraria y los cultivos en el mundo rural español utilizando una fuente de información desestimada hasta entonces: los datos del Catastro de Rústica, recogidos en el Ministerio de Hacienda. Aun con todas sus imperfecciones el Catastro es instrumento de primera mano para el análisis regional. Sus ideas acerca del valor de esta herramienta de análisis se recogen en El mapa de utilización del suelo según los datos del catastro, 1965, trabajo presentado al III Coloquio de Geografía celebrado en Salamanca, en el que aplica un artificio metodológico para la clasificación de las diferentes formas de utilización del suelo. Los valores cualitativos se obtuvieron según el método preconizado por la O.C.D.E. para determinar el grado de bienestar de la población rural. Dado el enorme volumen de información que fue necesario manejar, se realizaron los cálculos con un ordenador IBM del C.S.I.C. ubicado en todo un edificio de dos plantas, y al que cada dos o tres días "se le caía el sistema", sin que nadie aclarase en qué consistía la caída. La mayor preocupación del técnico responsable del ordenador era saber si los cálculos debían hacerse con "coma fija" o "coma flotante". Para no descubrir su ignorancia acerca de la tipología de las comas, cuenta el propio profesor Higueras, jamás tomó decisión al respecto, dejándola al arbitrio del técnico. La cartografía resultante, diez mapas de España a escala 1/1.000.000 no sólo da idea cabal de la repartición de los cultivos en aquel momento, sino que muestra cómo se puede sacar partido de las nuevas tecnologías, aunque al principio no se vea su utilidad. 
Cuando algunos años más tarde, el profesor Higueras hizo oposiciones a cátedra, pasó por alto este ingente trabajo, porque algún miembro del tribunal no entendía que los pueblos se identificasen por un código y no por su nombre.

En las primeras décadas del siglo XX, había en España una preocupación generalizada por la agricultura y, de manera especial por los regadios. Todo el mundo hablaba de regadíos, el primero Costa, pero antes de iniciar los grandes proyectos había que saber cómo se repartía la lluvia, cual era su volumen y el régimen anual e interanual de las precipitaciones. De estos estudios previos se encargaron geógrafos alemanes encabezados por Lautensach hijo, que realizaron diversas monografías sobre la climatología de la Península Ibérica. Una de estas monografías, la uiltima, corrió a cargo de H. Neumann y, supervisada por el profesor Higueras, se publicó con el título El clima del SE. de España en Estudios Geográficos en 1960. El estudio muestra claramente la existencia de diversas provincias climáticas en España con caracteres diferentes, desde las provincias marginales del Norte de carácter netamente continental, a la extrema sequedad de la cuenca de Granada y las altiplanicies de Guadix, Baza y Huéscar; o la mayor pluviosidad y menor temperatura de las provincias del interior frente a las propiedades termográficas de las provincias litorales. En la misma línea de estudios relacionados con la climatología agricola, años más tarde, en 1974, auspiciaba, en colaboración con los malogrados meteorólogos Ascaso y Liso otro trabajo relativo al clima: Indices de evapotranspiración potencial del Valle Medio del Ebro, realizado en la Estación Experimental de Aula Dei de Zaragoza, y que es una obra fundamental para el conocimiento real de las necesidades de agua de riego en la cuenca del Ebro.

Actualmente apenas se publican estudios de Geografía Regional, pero hasta mediado el siglo XX, y siguiendo la tradición de la escuela francesa de Geografía, la mayoría de los geógrafos se inclinaban por los estudios regionales. Lo que cambiaba era el centro de interés de cada uno, ya fueran hechos físicos o humanos, pero todos los estudios eran regionales, pues esa era, se decía, la esencia de la Geografía. El profesor Higueras no fue una excepción. Su tesis doctoral sobre El Alto Guadalquivir, estudio geográfico es una obra clásica de análisis regional con la que obtiene el título de Doctor en Madrid en 1960. A partir de este momento pasa a desarrollar una intensa labor profesional como "colaborador científico de carrera" en el C.S.I.C. y Jefe de la Sección de Micromorfología del Suelo del Instituto de Edafología y Fisiología Vegetal del C.S.I.C., también en 1960.

El Alto Guadalquivir "no es un modelo de Tesis", dice el autor, "pero sí resultado de mucho trabajo e ilusión". El subtítulo de estudio geográfico resume muy bien el contenido del mismo. Dirigido por el profesor Casas Torres trataba de ser una introducción al "Plan Jaén", un intento de colonización interior de España para detener el éxodo rural hacia las grandes capitales, como antes lo había sido el "Plan Badajoz". El libro fue publicado por el Instituto de Estudios Giennenses y el Departamento de 
Geografía Aplicada del Instituto Juan Sebastián Elcano del C.S.I.C., en 1961. Como buen humanista no olvida la historia, de la que es un buen conocedor. En la antigüedad el Alto Guadalquivir era el camino obligado para ir desde el Levante valenciano hasta la Bética, a través de la "depresión periférica" de Sierra Morena, que fue un descubrimiento geomorfológico del profesor Higueras, gracias al análisis realizado con la fotografía aérea de la zona. El interés de la depresión no sólo es geomorfológico, sino también estructural, porque es uno de los pocos lugares en los que aflora la "penillanura pretriásica del zócalo fundamental" de la meseta. Con acierto señala el autor las relaciones que siempre existen entre lo físico y lo humano: un hecho geomorfológico (la depresión periférica) explica la existencia de una ruta seguida por los pueblos peninsulares desde siempre. Hasta el siglo XVIII en que se abre Despeñaperros, no había más que dos caminos para llegar a Andalucía: el oriental del Campo de Montiel, es decir, el del Alto Guadalquivir, y el occidental de la Ruta de la Plata, de época prerromana.

El Alto Guadalquivir no se refiere únicamente al tramo alto del río. En él se incluyen también las tierras a uno y otro lado del valle (entre Sierra Morena al norte y las sierras Subbéticas al sur). El Alto Guadalquivir, dentro del mosaico regional que es Andalucía, disfruta de una posición intermedia entre la Alta y la Baja Andalucía. Es un dominio geomorfológico de características singulares, pero es también un dominio cultural y social muy diferente del resto de Andalucía. El profesor Higueras no olvida el significado del entorno natural, la esencia morfológica del Alto Guadalquivir, pero repara sobre todo en la "esencia cultural" del mismo que atribuye al dominio del olivar que, estas son sus palabras, "lo llena todo", dando lugar a un paisaje increíble si no se ve y en el que ya había reparado el poeta Machado desde su cátedra del instituto de Baeza. El cortijo, uno de los elementos culturales del paisaje del Alto Guadalquivir, no tiene nada que ver con el de las campiñas de la Baja Andalucía, salvo la denominación de "cortijo".

Tras una primera etapa de ejercicio profesional como edafólogo, accede por oposición, en 1965, al cuerpo de catedráticos de universidad ocupando la cátedra de Geografía de la Universidad de Santiago de Compostela y, posteriormente, por traslado, una de las dos cátedras de Geografía de la Universidad de Zaragoza (1966). En el marco de ambas universidades desarrolla su labor docente e investigadora, pero sobre todo en la de Zaragoza, donde todavía desempeña labores de investigación y de doctorado en su condición de Profesor Emérito.

Desde el primer momento de su llegada a Zaragoza asume responsabilidades científicas de dirección, como la de director del Instituto de Estudios Pirenaicos (hasta 1967), así como de la Sección de Geografía de la Población del Instituto de Geografía Aplicada del C.S.I.C. en Zaragoza. La labor docente en la Universidad de Zaragoza ha sido inmensa: cuarenta y dos tesis doctorales, sobre las cuestiones más diversas, y más de treinta tesis de licenciatura dirigidas en todos estos años. La varieclad de temas 
tratados demuestra su capacidad de geógrafo en los distintos ámbitos de la Geografía y su amplísima formación adquirida por el estudio, ciertamente, pero también por el trabajo de campo de la mano de eminentes geógrafos físicos como Luis Solé, Noel Llopis, Oriol Riba, Francisco Hernández Pacheco, y otros muchos, sin contar la convivencia con los geógrafos de la "Escuela" como los maestros Casas, Floristán, Ferrer y otros.

Para el profesor Higueras, la Geografía no es un cajón de sastre donde todo cabe. El geógrafo puede estudiar cualquier tema si lo encuadra debidamente en lo que él denomina el "Sistema Geográfico". De ahí que haya acometido el estudio de las cuestiones más diversas sin perder nunca de vista el horizonte geográfico. En el estudio de hechos de Geografía Humana suele recordar la afirmación de Le Lannou de que la Geografía Humana tiene por objeto el estudio del "Hombre Habitante". A partir de ahí, todo puede ser geográfico. Es el caso del estudio de las zonas de producción hortofrutícola y de los mecanismos de distribución y comercialización de las frutas y verduras en una gran ciudad como Madrid. El consumo de frutas y verduras en Madrid, publicado en 1966 en el homenaje al Excmo. Señor D. Amando Melón y Ruiz de Gordejuela, es un detallado estudio de Geografía Económica y del comercio al por menor en el que pone de relieve que la vitalidad del área submetropolitana rural de Madrid, lo que más tarde se definiría como espacio rururbano, estaba subordinada por entero a la capital.

Auténtico estudio de Geografía Social es La emigración interior española, libro publicado en 1967 por la editorial Mundo del Trabajo. Se trata de un cuidadoso análisis con abundantes reflexiones acerca de los movimientos geográficos de la población en la España de los años sesenta, que condicionaron el desigual desarrollo demográfico y económico de las regiones españolas.

Marcado carácter social tienen también sus trabajos sobre los regadíos. El regadío es una técnica de cultivo contrapuesta al secano, propia de países semiáridos como muchas zonas de España, donde constituye una necesidad. A mediados de los años sesenta, el regadío cubría en España, una extensión de 2.000.000 de hectáreas, esto es, aproximadamente un $10 \%$ de la superficie cultivada. El regadio se practicaba con técnicas ligadas siempre a las facilidades naturales para utilizar el agua (como las que dieron lugar a los regadíos tradicionales de Levante, la Vega de Granada y el Valle del Ebro, por ejemplo), o por medio de las nuevas técnicas de captación y bombeo desarrolladas en el último siglo. Pero al profesor Higueras le interesa resaltar los aspectos sociales del regadío en publicaciones como Los regadios en España (1964) comunicación presentada al Congreso de la Unión Geográfica Internacional en Londres; $L a$ agricultura de regadio en España (1969) publicada en el la miscelánea de homenaje al Doctor Canellas, y la Nota acerca de la economía del regadio aragonés (1972), también escrita con motivo de homenaje al profesor Casas Torres en sus veinticinco años como catedrático. Estas obras reflejan ideas originales, como la sugerencia de que "el 
interés de Aragón no está en producir más sino en vender mejor"; clara alusión sobre la conveniencia o no de ampliar los regadíos, y que se anticipa en treinta años a las polémicas sobre la política del agua.

El primero de estos trabajos sobre la agricultura de regadio en España es una sólida reflexión, apoyada en una amplia base estadística, sobre las ventajas del regadío en nuestro país mientras que en los dos restantes se analizan los factores ecológicos y económicos que rigen la agricultura de regadío. En el primero se estudian las condiciones climáticas y edáficas del regadío; en el segundo se valora y cuantifica lá aportación del regadío a la economía agrícola (en este caso Aragón). En ambos casos se trata de una puesta al día de los trabajos de los geógrafos franceses, Sorre y otros, que dos décadas antes habían estudiado los regadíos españoles. La oportunidad de estos trabajos estaba avalada por el intenso esfuerzo que se estaba haciendo para la transformación de secanos en regadios en el Valle Medio del Ebro, en las Vegas del Guadiana y en el Alto Guadalquivir. Durante muchas décadas la transformación del secano en regadío ha sido una preocupación nacional. Pero en todos sus trabajos referentes al regadio, el profesor Higueras advierte, desde su condición de edafólogo, de las dificultades que tendría que vencer la transformación de los secanos y los problemas que traería consigo: destrucción de las formaciones de rañas en las vegas altas del Guadiana, problemas de drenaje en las "Tierra de Barros" de Badajoz y los problemas de los suelos altamente salinos de Monegros (que él había estudiado en su época de becario de la Fundación March). A todo esto añade la sospecha de que en una economía abierta de mercado la producción que se obtenga será difícilmente competitiva, a no ser que se introduzcan plantas nuevas.

En todos estos trabajos se destaca la necesidad de regularizar los principales ríos españoles y tomar en consideración la naturaleza topográfica y litológica antes de emprender obras de transformación de secanos. Aunque el déficit de agua afecta a muchas regiones españolas, no siempre es aconsejable implantar nuevos regadíos. Hay una "cultura del agua" que no se aprende fácilmente. Los niveles técnico y socioeconómico alcanzados permiten ampliar la extensión del regadío, pero con ello podrían aparecer otros problemas de difícil solución: embarramiento, salinización, destrucción del suelo, etc. que cita en cada caso. Además, pone de manifiesto que "la organización del regadío español es tan minuciosa en ocasiones, y de ámbito tan restringido, que cada pueblo, cada acequia y cada término catastral suelen tener una regulación peculiar para el uso del agua". Por ello sintetiza la complicada organización del regadío español distinguiendo tres clases de regadío: a) los tradicionales, cuyo prototipo son los riegos de Levante y en especial la Real Acequia del Júcar y la organización de los pequeños ríos afluentes del Ebro; b) lo que denomina regadíos modernos, entre los que incluye los del Canal Imperial de Aragón, y c) los grandes planes de colonización que entonces se hallaban en fase de ejecución. Si estos planes se llevasen a cabo, España contaría con 3 millones de hectáreas de regadío, pero habría que dar solución a nuevos problemas. Por eso aunque admite que "la trans- 
formación de secanos en regadios es la verdadera revolución agrícola española", recomienda "pensar en los problemas de comercialización y excedentes agrícolas".

Como se ha indicado antes, en sus estudios sobre el regadio, el profesor Higueras incluye siempre aspectos sociales y socioeconómicos, como su importancia para el asentamiento de la población rural. En El consumo de frutas y verduras en Madrid, citado anteriormente, recalca la interdependencia que existía entre la gran ciudad y su entorno rural. La influencia urbana se extendía entonces hasta más de $250 \mathrm{kms}$. de la capital. La influencia de Madrid se proyecta también hoy sobre un radio de más de doscientos kilómetros, pero ha cambiado el signo de la influencia: Madrid, ya no demanda productos agrícolas de su entorno, sino suelo y vivienda. En conversaciones informales sobre estos temas suele decir que el 30\% de la huerta de Madrid está en Marruecos.

\section{Población, ciudades y desequilibrios regionales}

Al comienzo de esta líneas indicábamos que durante más de treinta años de su vida docente e investigadora, el profesor Higueras ha dedicado casi todos sus esfuerzos al estudio de la población, tanto desde el punto de vista demográfico, como de los asentamientos rurales y urbanos. La ciudad, como hecho geográfico, ha sido uno de sus centros de interés más persistentes. Los caracteres que definen el hecho urbano, la complejidad del concepto genérico de ciudad, la importancia del fenómeno urbano en el mundo, como uno de los rasgos más característicos de la civilización del siglo XX, y la necesidad de respuestas adecuadas al crecimiento urbano, son algunas de las reflexiones que el profesor Higueras expuso en la XXIV Semana Social de España, 1965, dedicada a "Problemas de concentración urbana", con un sugerente trabajo titulado Motivos de la concentración urbana. Insiste en la idea de que el geógrafo no se ha de limitar al estudio funcional de las ciudades, sino que ha de penetrar en el conocimiento de su estructura interna e interpretar el papel que desempeña como sistema de actividades, de prestación de servicios, de convivencia y de organización del territorio en el que se hallan situadas. Es la manera de huir de la simple enumeración de "lo que hay" en cada ciudad, que es, recalca el profesor Higueras, lo más ajeno a la Geografía. Por eso tiene gran importancia metodológica el artículo El papel del geógrafo en las investigaciones sobre el espacio urbano (1981). No se trata más que de unas simples notas acerca del modo en que debe conducirse un doctorando que inicia un estudio de Geografía Utbana (conviene recordar que el Profesor Higueras ha dirigido siete tesis doctorales sobre la ciudad de Zaragoza).

En ese breve texto toma como referente la ciudad de Zaragoza a la que subdivide en cuatro áreas urbanas: centro, ensanche (ambas forman el casco urbano), arrabales 
y área periurbana que tienen fisonomía y funciones específicas, pero carecen de vida propia, porque es la ciudad la que les da vida. Afirma que "al finalizar su trabajo, el geógrafo debe llegar a tener un conocimiento sintético e integrador del espacio urbano, pues ha analizado las condiciones de vida y la organización del espacio y está en condiciones de efectuar un diagnóstico sobre la situación demográfica, fisonómica y funcional en cada una de estas unidades urbanas. Pero el geógrafo no se ha de limitar solamente al diagnóstico. Debe proponer también soluciones concretas para la ordenación del espacio urbano". En su opinión la percepción que el geógrafo tiene del espacio urbano es diferente de la de otros profesionales. El geógrafo conjuga ideas urbanísticas del pasado, conoce las funciones que la ciudad ejerce y propone siempre ideas integradoras: "La historia no muere" y las ciudades son, ante todo, historia, por eso cambian de fisonomía, pero no mueren mientras desempeñen algún papel". Es el caso de Zaragoza con sus cardus y decumanus que persisten ante todo.

Atento siempre a las principales corrientes científicas observa que la Geografía Urbana se inserta dentro de las corrientes ecológicas de la Escuela de Ecología Humana de Chicago. La ciudad como fenómeno ecológico (1989) es un intento de difundir las teorías de la Escuela de Chicago. Para esta Escuela y su promotor Mckenzie, la ciudad es una comunidad de seres vivos asentada en un territorio donde se desarrollan actitudes y comportamientos de dominación territorial, competitividad, exclusión, etc; que se manifiestan a través de factores técnicos, sociales, administrativos y culturales, que son los modernos instrumentos del poder.

Desde una perspectiva diferente, el profesor Higueras reflexiona nuevamente sobre el significado geográfico de la ciudad en "New towns" en Espagne, trabajo publicado en Polonia (1989). La idea de las new towns se presta a múltiples interpretaciones, ya que se aplica a ciudades edificadas ex novo y a barrios construidos en la banlieue de las grandes ciudades para descongestionarlas o para instalar inmigrantes. En España son los programas de las ACTUR, situados siempre en la zona de influencia de una gran ciudad, los que presentan mayor similitud a las new towns.

La producción científica del profesor Higueras avanza en todos los frentes del amplio abanico de la Geografía. Cada tesis dirigida es la puesta en práctica de reflexiones anteriores. Pero sean cuestiones de Geografía Física o de Geografía Humana, hay un elemento de unidad: la necesidad de una exigente referencia espacial de los hechos geográficos y de su delimitación territorial. Esto atañe, sobre todo, a la delimitación espacial de los hechos políticos. Esta cuestión la aborda el profesor en Geopolitica y Geoestrategia. El concepto de Frontera en Geografía (1967). Desde lá posición del geógrafo, la frontera se ve como una zona de transición, de contactos, de interrelaciones y convergencias físicas o humanas. Descle otro punto de vista, la frontera se percibe como separación y es una noción fundamental no solo en el estudio de la Geografía Regional, sino también en la Geografía General, pues las grandes zonas, cualesquiera que sea su naturaleza, están sujetas a límites. 
La investigación geográfica, como toda investigación científica, se guía en parte por paradigmas, que en cierto modo equivalen a "modas". Hacia 1960 España había abandonado ya los esquemas socioeconómicos de la autarquía imperante desde la terminación de la guerra civil, y se iniciaba la época de los "Planes de Desarrollo" en los que primaban dos ideas fundamentales: elevar el nivel de vida de España como país y disminuir las grandes desigualdades regionales. En este momento, como la mayoría de los geógrafos de la época, el profesor Higueras presta su colaboración para el estudio de los problemas regionales. Junto con otros profesores, desarrolla nuevas ideas acerca de la región y los desequilibrios regionales en Algunos aspectos de los desequilibrios regionales españoles en 1967 (aportación española al XXI Congreso Geográfico Internacional) y, posteriormente, en Los desequilibrios regionales en España (1981) y en Cuestiones de desarrollo regional, que fue una aportación a la V Reunión de Estudios Regionales (1981).

Para el profesor Higueras los desequilibrios regionales, que se expresan en cifras, no tienen más valor que el que se quiera dar a los números. Sin embargo, los aspectos cuantitativos adquieren valor cualitativo cuando se comparan con los de otras regiones. Además, en la definición de desequilibrio intervienen apreciaciones subjetivas que valoran de muy diferente manera los mismos hechos. Siempre ha gustado de recordar el profesor Higueras que, "desde el punto de vista geográfico, antes de hablar de regiones equilibradas o desequilibradas, hay que ver como se ha hecho la división regional y cuál es el modelo de referencia". Son aclaraciones oportunas en unos momentos en que se intuía la conveniencia de elaborar una nueva estructura territorial para nuestro país basada en autonomías regionales, en cuya delimitación se conjugarían factores históricos, lingüísticos y geográficos.

En consonancia con lo que venia siendo objeto de atención preferente en el Departamento de Geografía de la Facultad de Filosofía y Letras de la Universidad de Zaragoza, el profesor Higueras retoma por esta época lo que había sido su primer centro de interés, el estudio de la población, pero ahora con nuevas perspectivas. Insiste en que el sistema demográfico del espacio rural y el del espacio urbano son interdependientes y en que su funcionamiento afecta al sistema social y económico en su conjunto. La población asalariada de Galicia (1978), publicada en el tomo de homenaje al profesor Otero Pedrayo, es una aportación al conocimiento de las condiciones de vida de la población gallega, en la que trata de salvar la laguna existente en el conocimiento estadístico de la distribución espacial y sectorial de la población industrial en Galicia. El análisis estadístico y la cartografía realizados (mapas de distribución municipal de la población industrial asalariada según ramas de actividad) le permiten concluir que la población industrial asalariada legalmente registrada en Galicia era entonces casi un $40 \%$ inferior a la estimada habitualmente.

Anteriormente había publicado otros trabajos de Geografía de la Población, entre los que entresacamos la Nota acerca del crecimiento de la población de Zaragoza 
1960-67 (1968), en donde Zaragoza se revela como un foco de atracción humana, esto es, de inmigración ya que, de hecho, actúa como motor de Aragón. Aquí se pone de manifiesto que la atracción que ejerce la ciudad de Zaragoza trasciende los límites provinciales y regionales, pero se deja sentir sobre todo en las provincias próximas, a la vez que Teruel proporciona más del doble de inmigrantes que cualquier otra provincia. A este respecto es muy expresivo el mapa realizado acerca de la procedencia de la inmigración a Zaragoza en los años sesenta que aparece en el librito ya citado de La emigración Interior en España. Se pregunta el autor cuál es el fundamento de la atracción demográfica de la ciudad de Zaragoza después de la guerra civil y la relaciona con el esfuerzo de implantación industrial realizado desde la promulgación del I Plan de Desarrollo y la creación en Zaragoza de un Polo de Desarrollo Industrial.

En Estructura demográfica de la provincia de Zaragoza (1975), que pone de manifiesto la evolución demográfica de la provincia, describe el modelo de creación de nuevos espacios industriales apoyados generalmente en las grandes arterias viarias y en las ciudades medias. Pero sobre todo insiste en la remodelación de la tradicional actividad agrícola y en el cambio de la dinámica demográfica de las áreas rurales que ofrecían ya entonces una estructura demográfica muy inestable, que ha conducido a la situación actual de "déficit demográfico". Centrado ya en el estudio de cuestiones de población, coordina un exhaustivo estudio sobre La población del Valle Medio del Ebro. Distribución espacial y equipamientos publicado por el C.E.S.I.E. (Consejo Económico Sindical Interprovincial del Ebro) en 1975, y que ha servido de base para otros estudios semejantes en épocas posteriores.

Aceptando que la noción de equilibrio espacial procede del campo de la economía, si los geógrafos admitimos que la región es un hecho fundamentalmente humano, es evidente que la eficacia regional del sistema económico habrá que medirla en función del hombre; de sus condiciones de vida, de la calidad de ésta y de su capacidad de desarrollo. La actuación del hombre genera desigualdades regionales de ahí que, el rofesor Higueras, considere más lógico que los geógrafos hablemos de desigualdades que de desequilibrios regionales. Insiste en que lo espacial constituye la esencia del trabajo del geógrafo. Es una idea machacona que repite una y otra vez y que le llevó a concluir que "si se prescinde del espacio, la Geografía pierde su razón de ser". Por eso en su obra se insiste mucho en el papel de las comarcas (territorio) en el desarrollo regional, como en Las comarcas ante el desarrollo regional (1976). A su vez El sector agrario en Aragón (1979), y la presentación que escribió para Tablas input-ouput y cuentas regionales de la economia aragonesa (1981), constituyen documentos de primer orden para un acertado diagnóstico de la situación socioeconómica de Aragón. Economía y Geografía se dan de nuevo la mano en estudios similares aplicados a la Rioja, como Tablas input-ouput y cuentas regionales de la economia riojana" (1983) y en El espacio agricola riojano (1989).

En 1981, recién estrenada la autonomía aragonesa, se implica como director y redactor de varios capítulos en la Geografía Regional de Aragón (1981-1983) en seis 
volúmenes, una de sus obras más queridas. A lo largo de los seis volúmenes de más de 300 páginas cada uno, se hace un estudio exhaustivo de las características naturales y sociales de Aragón a diferentes escalas, regional y comarcal. En este caso se trata de comarcas concebidas con criterios geográficos y funcionales que han servido, sin duda, para la elaboración de otros mapas comarcales.

Para el profesor Higueras, Geografía y territorio es una misma cosa. Conocer el territorio y sus problemas y potencialidades es hacer Geografía. En el Estudio conjunto de los problemas comunes de las tres provincias aragonesas (1971) resalta la personalidad regional de Aragón como base para su promoción dentro de los planes de desarrollo, entonces vigentes. No en vano fue miembro de la Ponencia de Desarrollo Regional del I Plan de Desarrollo (1967-1971), a la vez que reflexiona sobre lo que se juega el ser regional de Aragón en Aragón, años setenta, conferencia publicada en 1973 por la Excma. Diputación Provincial de Zaragoza. Es una llamada de atención hacia el futuro que se avecina, un futuro que, sin ser futurólogo, acierta a prever con notable antelación, aunque desafortunadamente muchas de las cuestiones sobre las que ha llamado la atención han tardado más de una década en ser tomadas en consideración. Es lo que sucedió, por ejemplo, cuando hace ya veinte años comenzó a hablar de los problemas de la baja natalidad en Aragón. Entonces, en reuniones y congresos, tuvo que soportar críticas sesgadas por los prejuicios a las que no respondió por no entrar en polémica. Pero aquí están ahora los efectos de las previsiones de entonces.

\section{Trabajos sobre dinámica demográfica}

Como hemos indicado anteriormente, en los últimos treinta años el profesor Higueras casi no ha hecho otra cosa que ocuparse de los problemas demográficos de Aragón, ya en forma de Cursos de Doctorado, en comunicaciones a congresos o en proyectos de investigación. Su gran preocupación es la despoblación de Aragón y sus consecuencias. Como es sabido, Aragón es una región con grandes desequilibrios demográficos provinciales y comarcales. La penuria demográfica no es de ahora, cuantitativamente hay grandes extensiones de territorio que no alcanzan los 5hab/Km.2 y muchos topónimos aluden a la histórica escasez de población ("desierto cle Calanda" "desierto de la Violada", etc.).

Aragón es una región demográficamente empobrecida por la emigración y la baja tasa de crecimiento vegetativo. El envejecimiento relativo de la población es uno de los más altos de España y lo mismo sucede con el indice de fecundidad, especialmente en las áreas rurales. Todo esto plantea graves problemas de ordenación del territorio. El profesor Higueras ha acuñado un término nuevo: el "déficit demográ- 
fico", interesante concepto que relaciona la eficacia de la población y el desarrollo sostenible. El déficit demográfico, tal como lo interpreta el profesor Higueras no es un concepto cuantitativo, sino cualitativo que guarda una estrecha relación con la población, la estructura económica y la identidad regional. En los últimos años setenta ya vislumbraba la necesidad de potenciar demográficamente las comarcas. Han tenido que pasar casi tres décadas para que las Instituciones tomasen conciencia de esta necesidad.

Al comienzo de estas líneas hacíamos mención a la inicial vocación pedagógica del profesor Higueras. Siempre ha estado atento a los cambios de concepto y método que aparecían en las revistas de Geografía. En los muchos congresos internacionales en los que ha participado, asistía siempre a las sesiones donde se exponían conceptos y métodos nuevos. Escuchaba, reflexionaba y, ya de vuelta en España, intentaba incorporar a sus clases lo que le parecía acertado. En Marzo de 1978 escribe para la Revista Bachillerato del Ministerio de Educación y Ciencia un trabajo sobre las Nuevas tendencias de la Geografia inclinándose por incorporar a la didáctica geográfica del bachillerato algunas técnicas nuevas, pero manteniendo lo esencial de la Geografía tradicional, para no confundir a los alumnos.

Pero en todo caso es decidida la apuesta del profesor Higueras por los estudios de población en la última etapa de su vida profesional, lo que le ha llevado a especializarse en estas cuestiones. Suele decir que la observación de cuanto ocurre en el mundo afecta a la población, y que la simple lectura de la prensa diaria es un observatorio de la realidad demográfica mucho mejor que las estadísticas oficiales. Cuenta con humor que cuando preparaba una comunicación sobre "La Inmigración Extranjera en Aragón" para un congreso, un alto cargo del Instituto Nacional de Estadística le aseguró que en la provincia de Zaragoza había solamente 60 subsaharianos. Intentó convencer a su interlocutor de que la cifra no era correcta, pero no hubo manera. "¿Cuantos hay?", preguntó el alto cargo. "Sólo en Zaragoza, 2.500", respondió el profesor. "¿Cómo lo sabe?", se le volvió a preguntar. "Porque los he contado", fue su respuesta. El alto cargo no se lo creyó, pero era cierto: juntos habíamos estimado la población de color que había en Zaragoza en aquel momento. Tal vez el alto cargo haya cambiado ya hoy de opinión.

La situación de acelerado cambio demográfico que está viviendo el mundo y los efectos que ello produce no dejan indiferente al profesor Higueras, que actualmente trabaja en una línea de investigación que ahonda en el análisis de los factores de variación de los sistemas demográficos, a escala regional y local. A las variaciones del sistema demográfico regional, se refería ya en Reflexiones acerca de los movimientos de población (1981). Comentaba allí cómo en los estudios territoriales de población, además del crecimiento vegetativo, los desplazamientos de población y las consecuencias que de ellos se derivan, había que tener en cuenta también "las mutaciones del espacio social". Desarrolla el concepto de "movilidad social" e iden- 
tifica las dos direcciones en las que actua. De una parte, estaría la movilidad territorial, que hace que las personas se desplacen de un lugar a otro recorriendo a veces grandes distancias y asumiendo infinidad de riesgos. De otra, hablaríamos de una "movilidad social", la que facilita el cambio social y la mejora del nivel de vida mediante el fenómeno de la "capilaridad social". Ambos tipos de movilidad debieran ir unidos, de manera que la movilidad territorial (las migraciones) no tendría justificación sin la posibilidad de mejorar las condiciones de vida. Pero esto no sucede siempre.

En estos trabajos sobre las migraciones, el profesor Higueras insiste en que la posición que las personas ocupan en la estructura social es el resultado de la "consideración" social de que gozan en el grupo, es decir, del lugar en el que las otros los colocan de acuerdo con el sistema de valores vigente. La aceptación del extraño, "el otro" no se produce por criterios objetivos, sino por criterios que valoran el grado de integración en el sistema social vigente. Por eso, en las encuestas al uso nadie se declara racista, porque no se rechaza la etnia, sino la no integración del inmigrante en el sistema. La relación entre movilidad geográfica y movilidad social es en todo caso la idea fundamental desarrollada por el profesor Higueras en este tipo de trabajos, al considerar que "los cambios de población hay que verlos como un aspecto de la movilidad social, que se manifiesta, entre otras maneras, en la movilidad geográfica, que es uno de los caracteres que con mayor efectividad inciden en nuestros actuales modos de vida".

El trabajo que comentamos es todavía más rico en sugerencias. Cuando no se tiene una posición social que asegure la tolerancia y la estima de la colectividad, a los extraños se le hace más difícil la convivencia con la población autóctona. La sociedad de acogida exige con frecuencia que los inmigrantes renuncien a convicciones personales muy íntimas. Las anteriores reflexiones provienen del estudio de las migraciones exteriores, pero pueden aplicarse a cualquier tipo de migración. La observación de que las principales corrientes migratorias interiores van de las áreas rurales a las urbanas, obedece al hecho de que en estas últimas se ofrecen medios de promoción social que no tienen las primeras. Las dificultades de cambio social, el inmovilismo en las zonas rurales y las diferencias cualitativas entre los rural y lo urbano impulsan a la emigración. Pero el profesor Higueras nos hace observar la paradoja de que "allí donde más difícil es la convivencia (la ciudad), y donde se da el individualismo más feroz, es donde se concentran los medios de promoción económica, profesional y cultural".

Al hilo de las reflexiones anteriores, el autor introduce múltiples conceptos e ideas fundamentales en Geografía Humana (sobre todo relativos a la Geografía de la Población y Geografía Social): crecimiento y cambio demográfico, cambio social, movilidad geográfica y movilidad social, estructura social, sociedades cerradas y abiertas, área cultural, emigración, diferencias cualitativas mundo rural y urbano, 
importancia de la renovación del conocimiento (lo que denomina la "imaginación creadora"), la noción de nivel de vida y su valoración (indicadores) etc. En la Geografía el espacio físico no es la única realidad a tener en cuenta. Por ello insiste en que es necesario considerar también muy detenidamente el espacio social.

Se ha convertido en un tópico el decir que en España se tiene una visión distorsionada de Aragón, porque Zaragoza capital equivale por sí sola a todo Aragón. Por eso, el profesor Higueras ha tratado de reflejar objetivamente la realidad demográfica de Aragón. Cuando hace más de diez años dijo por primera vez que en Aragón había 500 pueblos "biológicamente muertos", nadie le creyó. Hoy, sin embargo, se habla de que hay más de 500 pueblos en "coma demográfico". La primera llamada de atención se dio con la publicación de la Estructura y perspectivas demográficas de Aragón. Primera parte (1985). La situación demográfica de Aragón en los años ochenta, se caracteriza por un acelerado proceso de envejecimiento y un escaso crecimiento vegetativo que se manifiesta en grado desigual a lo largo del territorio. En un total de doscientas cuarenta y tres páginas se presenta el cálculo de las perspectivas demográficas y la expresión gráfica de la estructura demográfica de todos los municipios y comarcas aragonesas. Esto permite apreciar los desequilibrios demográficos comarcales de Aragón, que no son sino el resultado de las vicisitudes socioeconómicas por la que ha atravesado la región en el último siglo, las cuales provocaron una fuerte emigración que dejó semidespobladas extensas áreas del territorio. En el trabajo se incluyen las pirámides de población en cifras absolutas y relativas para todos y cada uno de los municipios y comarcas de Aragón, con el objetivo de facilitar una más acertada comparación de la estructura demográfica de cada uno de ellos. Constituye, por tanto, una detallada radiografía de la situación demográfica de Aragón, primer paso para elaborar las proyecciones de la población aragonesa al horizonte 1991 y 2001.

En la segunda parte del estudio, que lleva el mismo título, pero con otro contenido, Estructura y perspectivas demográficas de Aragón. Segunda parte (1988), se presentan las estimaciones de población para cada una de las comarcas aragonesas, explicando las dificultades metodológicas que comporta un estudio de estas características. En el trabajo queda en evidencia que "cuanto menores son las unidades demográficas, mayor es la dificultad; y al proyectar la estructura por intervalos de edad, como en este caso, las dificultades crecen espectacularmente". A pesar de todo, la utilización de un modelo de elaboración propia permitió realizar unas proyecciones con un error en conjunto inferior al 3\% y mucho menor para los núcleos de población de más de 2.000 habitantes. El modelo de cálculo utilizado era cloble. De una parte se estimó la población cerrada y, de otra, la población abierta, que es la que presenta mayores dificultades metodológicas porque tienen en cuenta la dinámica natural de la población y las migraciones. En el estudio se advierte que la división comarcal utilizada es una de las muchas que podrían hacerse en Aragón y no pretende ser definitiva. La información numérica y gráfica de cada comarca era tam- 
bién de indudable interés ya que "prácticamente todos los organismos encargados de la planificación regional y de la organización del territorio se ven en la necesidad de hacer este tipo de proyecciones".

La última parte del estudio sistemático de las perspectivas demográficas de Aragón comprende tres volúmenes, uno por provincia con todos sus municipios: Perspectivas demográficas de Aragón. Tercera parte: municipios. Provincia de Huesca; Perspectivas demogräficas de Aragón. Tercera parte: municipios. Provincia de Zaragoza y Perspectivas demográficas de Aragón. Tercera parte: municipios. Provincia de Teruel". Todos ellos fueron publicados por la Real Sociedad Económica Aragonesa de Amigos del País (1991). La metodología es la misma que la utilizada para la estimación de la población futura de las provincias y de las comarcas, citadas anteriormente, y con el horizonte del año 2001. En total son más de 300 páginas en las que con diez años de antelación se vishumbra la crisis demográfica de Aragón, como ha demostrado el Censo de Población realizado en 2001.

La originalidad del trabajo del Profesor Higueras, en el que tuve la oportunidad de colaborar, es que no realiza proyecciones, sino que observa la tendencia de la evolución demográfica y cuantifica los resultados probables de esa tendencia en una fecha no muy lejana: diez años. En realidad el método que sigue es el del demógrafo francés Henry, para quien las proyecciones se convierten en perspectivas cuando las hipótesis de partida son moderadamente verificables. Pero para ello es necesario conocer las características de la población cuya tendencia de crecimiento se analiza. Por eso el profesor Higueras no habla nunca de proyecciones, sino de previsiones demográficas, que alcanzan un alto grado de cumplimiento cuando las hipótesis en las que se apoya el cálculo tienen en cuenta la realidad socioeconómica del espacio analizado. A lo largo de la década de los noventa, ha seguido con atención la evolución demográfica de las provincias aragonesas, de las comarcas y de los municipios, actualizando en cada caso el modelo original que, conviene decirlo, ha necesitado muy pocos recortes, salvo en lo referente a la inmigración extracontinental. Con motivo del III Congreso de Economía Aragonesa, organizado por la Diputación General de Aragón, la Facultad de Ciencias Económicas y Empresariales y el Colegio Oficial de Economistas de Aragón, en el que, entre otras cuestiones, se estudió la evolución previsible del mercado de trabajo, se puso de manifiesto una vez más, que las Perspectivas demográficas de Aragón eran acertadas. El modelo predictivo propio, aplicado en los estudios anteriormente citados se comparó con los tradicionales de Lotka, Rogers, Henry y otros, resultando que se ajustaba mucho mejor que los tradicionales a la realidad aragonesa.

El análisis demográfico de Aragón, realizado ininterrumpidamente por el profesor Higueras a lo largo de su dilatada carrera investigadora en la Universidad de Zaragoza, le ha permitido estudiar un tema que ahora preocupa a la sociedad y a todas las instituciones: El envejecimiento de la población aragonesa. Desde sus pri- 
meros trabajos sobre Aragón (Estudio conjunto de los problemas comunes de las tres provincias aragonesas, Aragón, años setenta, Estmuctura demográfica de la provincia de Zaragoza, etc), el profesor Higueras destaca que el mayor problema que tiene el sistema demográfico de Aragón es el envejecimiento de su población, tema que da título al artículo publicado en un número monográfico de Papeles de Economía Española, dedicado a Aragón (1991). El concepto de envejecimiento y las causas que lo producen dan entrada a la observación de que el crecimiento de la capital regional se ha hecho a expensas del despoblamiento de las áreas rurales, que son las que acusan, por eso mismo, las mayores tasas de envejecimiento. El proceso de envejecimiento se manifiesta en Aragón mucho antes que en otras regiones españolas sobre todo por los tempranos flujos de emigración que se registran en la región. Estimaba que "no se le daba la suficiente importancia al envejecimiento relativo de la población", probablemente porque la población potencialmente activa se ha mantenido constante, gracias a la elevada natalidad de los años sesenta. Sin embargo, con la caída de la natalidad actualmente aumenta la tasa de dependencia por vejez debido al alargamiento de la vida. Las crecientes tasas de dependencia por envejecimiento estaban creando una situación nueva caracterizada por los elevados costes sociales de la población envejecida, entre la que de día en día se incrementa el grupo de los "viejos-viejos".

El problema sociodemográfico del envejecimiento de la población en los países desarrollados de Europa es el centro de la lección pronunciada por el profesor Higueras en la inauguración del Curso Académico 1992-93 de la Universidad de Zaragoza, y que versó sobre el tema: La población mundial hacia el Tercer Milenio (1993). En la introducción recuerda que el principal problema demográfico del mundo actual no es el ritmo de crecimiento de la población mundial, sino la evidente desigualdad entre unos pueblos y otros que se traduce en insufribles situaciones de injusticia social, económica y política: un quinto de la humanidad disfruta del $85 \%$ de la renta mundial, mientras que las $4 / 5$ partes de los hombres deben contentarse con el restante $15 \%$.

Hecha esta primera observación, comienza la lección - que está naturalmente publicada- recordando que, desde su formulación, los más afamados demógrafos pusieron en duda la "ecuación de Malthus", ya que los ritmos y fluctuaciones de la natalidad y la mortalidad no son constantes, sino que evolucionan de acuerdo con variables exógenas propias de cada lugar y de cada momento. Algunas de estas variables, recuerda citando a Vershult, son retardatorias del crecimiento, es decir, constituyen "obstáculos". El profesor Higueras afirma que tales obstáculos existen y que influyen en los ciclos demográficos, los cuales cambian de acuerdo con el marco socioeconómico de cada momento. Apoyándose en la variabilidad de los ciclos demográficos enuncia una sugerente teoría acerca de una nueva transición demográfica a lo largo del siglo XXI, que tiene en cuenta el progresivo envejecimiento relativo de la población. 
A lo largo de la lección va desgranando la situación demográfica que se da en la mayoría de los países de Europa, donde se ha optado por el crecimiento demográfico cero, sin tener en cuenta las consecuencias negativas de esta actitud en un futuro próximo; lo que ya había sido previsto por Sauvy. Recuerda la preocupación de los expertos por cuestiones como el vertiginoso crecimiento de la población, la disminución de la fecundidad, el crecimiento cero, o el envejecimiento relativo de la población de los países desarrollados; temas a los que se añaden las corrientes migratorias legales e ilegales, y los desplazamientos masivos de la población, que tantos problemas ocasionan en los países de origen y de llegada. Ciertamente todas esas cuestiones preocupan hoy a geógrafos demógrafos, economistas, sociólogos y políticos, pero muy pocos - en su opinión- se ocupan de estudiar las consecuencias de la actual tendencia demográfica de la vieja Europa, vieja por su historia y vieja por su población. Refiriéndose a Aragón vaticinaba: "de no cambiar la tendencia, sobrarán escuelas en los pueblos y faltarán asilos”. A día de hoy vemos, una vez más, cómo las previsiones demográficas del profesor Higueras se han cumplido.

\section{Despoblación rural y medio ambiente}

El rápido crecimiento de la población urbana y el despoblamiento progresivo de las áreas rurales es, como estamos viendo en esta miscelánea, uno de los centros de interés del profesor Higueras. En 1991 edita Rural depopulation, un libro que recopila los trabajos presentados en la reunión de la sección de Geografía de la Población que tuvo lugar en Zaragoza dentro de la celebración de la Conferencia Regional sobre países mediterráneos, organizada por la U.G.I. en Barcelona (1986). En el libro se presentan diferentes ejemplos de despoblación rural en el mundo y el propio profesor incluye un trabajo denominado Depopulation in mural áreas in Spain 1959-1985, en el que expone las causas más importantes en el proceso de despoblación de las áreas rurales en España.

Poco más tarde, en el libro homenaje al profesor Vilá Valentí (1999) ahonda en las Características de la población miral española, dudando de la validez del criterio que en el análisis geográfico diferenciaba tradicionalmente la población rural y la población urbana. Tomando la etimología de la palabra "rural" en su sentido más amplio (nus, miris), podría concluirse que lo rural y lo urbano se refieren en el fondo a categorías socioeconómicas y socioculturales. Pero desde el punto de vista geográfico son importantes otros elementos como la "localización" (locus) y la situación (situs) que son inseparables del status. No es fácil llegar a una definición de población rural, señala el profesor Higueras, porque la mayoría de los criterios que se utilizan para definirla son imprecisos e insatisfactorios. La oposición campo-ciudad es cada vez menos percepti- 
ble. El análisis de la población rural plantea, pues, problemas metodológicos que no han sido satisfactoriamente resueltos y obligan a reflexionar sobre las diferencias entre lo rural y lo urbano desde perspectivas diferentes de las tradicionales.

En su análisis de la población rural española se observa que las características demográficas que la singularizaba hasta hace tan solo medio siglo, en cuanto a mortalidad, natalidad y movilidad, han cambiado bruscamente, de manera que están desapareciendo de forma acelerada las diferencias que separaban, desde el punto de vista demográfico, al mundo rural del mundo urbano. Las tasas de mortalidad, por ejemplo, son semejantes en las áreas rurales y en las urbanas. En Les inegalités geographiques de la mortalité (1991), el estudio de la mortalidad diferencial en cincuenta provincias españolas realizado con técnicas de análisis factorial y utilizando las diez variables con mayor incidencia aparente sobre la mortalidad, se confirma que el clesarrollo socioeconómico y el aumento del bienestar tienen una influencia directa en la regresión de la mortalidad y en la prolongación de la vida en el conjunto del país. A pesar de que aún permanecen diferencias regionales remarcables, todo parece indicar que el país se encuentra en proceso de igualación en lo que se refiere a la esperanza de vida al nacer, lo que interpreta como resultado de los profundos cambios socioeconómicos ocurridos en España desde finales de los sesenta.

Lo mismo sucede con la natalidad. Las actitudes y comportamientos de la población respecto de las variables demográficas son muy semejantes en las áreas rurales y en las urbanas. En su opinión "el factor diferenciador de la dinámica demográfica rural y urbana respecto de la natalidad, ya no estaría hoy en las estructuras mentales y socioeconómicas, sino en la estructura de la población". En la mayor parte de las áreas urbanas la población mayor de 65 años tiene un peso desproporcionado, en muchos lugares superior al $40 \%$, lo cual influye, lógicamente, en todas las variables demográficas. La baja densidad de población y el alto grado de envejecimiento relativo son las principales causas de lo que en este trabajo se denomina "ruina demográfica" del mundo rural y en otros lugares "déficit demográfico".

A lo largo de esta semblanza hemos hecho notar en numerosas ocasiones que el profesor Higueras no se limita a describir los fenómenos que estudia, sino que intenta penetrar en la naturaleza íntima de los mismos. Su obsesión son los sistemas: "Los elementos aislados no tienen significado en Geografía; lo importante son los sistemas complejos en que esos elementos se integran y el papel territorial que desempeñan". Ante cualquier nueva cuestión relativa a un sistema demográfico, ya sea local, regional o nacional, no la acepta o rechaza sin más, sino que reflexiona sobre ella e intenta darle una interpretación coherente, dejando de lado las teorías admitidas, si son insuficientes para explicar el hecho de que se trata. A menudo da a conocer los resultados de su trabajo en foros nacionales e internacionales, causando a veces sorpresa, como cuando ha hablado del déficit demográfico o de la degradación medioambiental por envejecimiento de la población. 
A la idea del "déficit demográfico" llega el profesor Higueras por el estudio de la evolución demográfica de Aragón en los últimos treinta años. El seguimiento continuo de la compleja evolución demográfica de la población aragonesa permite hablar del déficit demográfico en nuestra región, un concepto fundamentalmente cualitativo, como se ha dicho anteriormente. La primera vez que se plantea un estudio de esta naturaleza en Aragón es en un trabajo titulado El déficit demográfico de Aragón. El área de Monzón (1996). Se trata de un ensayo para la puesta a punto de la metodología utilizada para el cálculo del déficit demográfico. Las consecuencias del déficit demográfico, en su mayor parte negativas, son de orden político, económico, social y administrativo. Esta situación dificulta la articulación de una adecuada política de ordenación del territorio y acentúa los desequilibrios internos. La conclusión a la que se llega es que ante una situación demográficamente deficitaria caben dos soluciones: "una a corto plazo consistente en elaborar una adecuada política de inmigración que atraiga población, incluso extranjera; otra, a más largo plazo, basada en una convincente política de familia".

La emigración que ha experimentado Aragón a lo largo del siglo XX es la principal causa del actual "déficit demográfico" que padece la región. Pero a ello hay que añadir la brutal caída de la fecundidad en los últimos treinta años, que en la mayoría de los casos guarda una estrecha relación con la emigración, aunque no sea ésta la única causa.

En el trabajo Fertility and social change in Spain (1975-1987), aportación al simposio internacional "The geographical approach to fertility" celebrado en Kiel (Alemania) en 1989 y organizado por la Comisión de Geografía de la Población de la Unión Geográfica Internacional, el profesor Higueras puso de manifiesto que uno de los acontecimientos demográficos recientes mas llamativos en Espana había sido la brusca caída de la fecundidad desde 1975, contraviniendo las proyecciones precedentes y conduciendo al crecimiento cero y al envejecimiento progresivo de la población. La tesis que sostiene en este trabajo, que se publicó en 1991, es que, como señala en el título del artículo, aceptando otros argumentos económicos y sociológicos explicativos, la caída de la fecundidad en España no se explica sino como resultado de la transformación social que se produjo en el país en el llamado periodo de transición política de España.

En el Congreso Internacional de la Unión Geográfica Internacional de La Haya (1996) la Comisión de Población pasó a denominarse de "Población y Medio Ambiente". Por eso, el profesor Higueras insistió más en una línea de trabajo que no le era indiferente: las relaciones entre la población y el medio. En esta línea de investigación cabe situar algunos trabajos como: The present situation in Spain regarding the transformation of arid land into irrigated land, tema presentado en la conferencia sobre Población y Medio Ambiente en regiones áridas, organizada por UNESCO/IUSSP/IGU en Aman (Jordania). En este trabajo se analizan las ventajas y 
los inconvenientes de la transformación de secanos en regadío. Allí queda claro que el regadio admite infinidad de variantes y que no tienen los mismos efectos en todas partes, entre otras cosas porque el término aridez expresa realidades muy diferentes. El modelo que sirve de ejemplo es el de los regadíos del valle medio del Ebro. También se alude a un primer Plan Hidrológico Nacional elaborado en 1995.

Las mismas ideas se hallan en Two examples of environmental transformation in dry Spain, trabajo incluído en una obra colectiva internacional ("Population and environment in arid regions", 1998), en el que partiendo de la necesidad del regadío en España, muestra que la transformación del secano en regadío no es solo un problema técnico, sino que requiere la acción coordinada de economistas, sociólogos, demógrafos y políticos, para lo cual estudia con mayor profundidad dos ejemplos, el caso de Extremadura, en concreto las "Vegas" del Guadiana, y el Valle Medio del Ebro.

Desde otro punto de vista, que guarda relación con el "déficit demográfico", el profesor Higueras estudia la relación existente entre emigración, despoblación y envejecimiento, y degradación medioambiental. Como hemos indicado anteriormente, se trata de una observación que no había sido resaltada antes en los estudios de geografía de la población. Como en otros trabajos innovadores, la idea inicial proviene de la observación de la realidad aragonesa: Degradation environnemental causée par l'emigration et le vieillissement de la population dans les zones de montagne d'Aragon (Espagne). La originalidad de este trabajo, presentado al Simposio internacional sobre población, medio ambiente y pobreza (Rabat, 1997), reside en que introduce un nuevo enfoque en el tema. Efectivamente cuando se habla de degradación medioambiental, suele hacerse referencia a los agentes activos de la misma, por ejemplo la excesiva densidad de población que ejerce una perjudicial presión sobre el medio ambiente. Pero el profesor aborda la degradación del medioambiente mediante lo que él denomina "degradación pasiva", o la consecuencia del abandono progresivo de espacios tradicionalmente ocupados, (como se produce en los espacios de montaña objeto de estudio), en zonas de agricultura primitiva o en zonas de difícil acceso.

Es precisamente la idea de la "degradación pasiva", entre otras consideraciones socioeconómicas, lo que le lleva a concretar los conceptos de despoblación y déficit demográfico en el trabajo que presentó en Dundee (Escocia) en 1998, en la Comisión de Geografía de la Población y Medio Ambiente, y que se publicó algo más tarde, con el título "Does a demographic deficit exist?", en la revista Applied Geography (2000). Como en tantas otras ocasiones, vuelve a aplicar la teoría de sistemas para mostrar que el declive demográfico puede actuar como un catalizador de la degradación medioambiental. Esta idea queda muy bien sintetizada en un interesánte esquema gráfico. Del debate expuesto en el artículo, se extraen varias conclusiones: el déficit demográfico no es un concepto absoluto; se pone de manifiesto, sobre todo, por la pérdida de eficacia en el sistema socioeconómico y ambiental debido a la escasez e ineficiencia de la población por envejecimiento. El desarrollo de este proceso 
conduce al empeoramiento de las condiciones de vida y a la imposibilidad de mantener un desarrollo sotenible.

Otro trabajo que también relaciona la población y el medio ambiente es el titulado Turismo, paisaje y medioambiente. Reflexiones geográficas. Se trata de un artículo incluído en una publicación sobre el turismo en Cuba, en el marco de las relaciones de la Cátedra José Martí de la Facultad de Filosofía y Letras de la Universidad de Zaragoza y el Departamento de Geografía de la Universidad de La Habana. En él resalta el fenómeno del turismo como "un hecho social que juega también un importante papel cultural y, en algunos casos, hasta político". Sin embargo, advierte también de los peligros a los que la ocupación intensiva del espacio físico, justificada solamente por estímulos económicos y sin planificación previa, puede conducir: a corto plazo, a la degradación del medio ambiente; y a más largo plazo, a la destrucción de los atractivos turísticos y, por lo tanto, al agotamiento del recurso.

\section{Conclusión}

Una experiencia docente e investigadora tan densa en contenidos y larga en el tiempo ha dado como resultado un libro titulado Teoría y método de la Geografía (Introducción al análisis geográfico regional) actualmente en prensa, editado por las Prensas Universitarias de la Universidad de Zaragoza. Me consta que el profesor Higueras ha dedicada más de doce años a la redacción del libro. Siguiendo la tradición de los grandes maestros de la Geografía francesa, ha querido cerrar con esta obra su labor docente. Pero aunque él dice que la "Teoría y Método de la Geografia" es su última obra, en realidad no es ni siquiera la penúltima. En el mes de Septiembre de 2002 participó en Curitiba (Brasil), junto con otros profesores de las universidades de Santiago de Compostela, de León y de Zaragoza, en un curso sobre Fronteras y globalización en Europa. Así mismo la Universidad de Varsovia ha solicitado su colaboración en el tomo homenaje que se va a dedicar al profesor Rosciszewski, Doctor Honoris Causa por la Universidad de Zaragoza y recientemente fallecido. Rara es la semana que no es solicitada su colaboración en algún evento relacionado con la Geografía.

Lo dicho hasta aquí no constituye más que una breve aproximación a la ingente obra cientifica del profesor Higueras. Estas páginas no recogen más que los aspectos más relevantes de su investigación científica en el campo de la Geografía y anteriormente en el de la Edafología. De sus conocimientos, experiencia y dedicación mucho podemos aprender sus discípulos. A su vez las más de cuarenta tesis doctorales y otras tantas tesis de licenciatura dirigidas, hablan de su inquietud científica y dedicación a los alumnos. Sus proyectos y su ambición científica no siempre han llegado a término, o lo han hecho sin dificultades. En 1971 comenzó la elaboración de un Atlas Regional 
de Aragón. En su momento fue una gran idea pero por diversas vicisitudes no llegó a editarse. La mayoría de las láminas están empaquetadas y han quedado obsoletas, pero andando el tiempo serán una referencia histórica. Tampoco fue posible contar con una Cátedra de Geografía Urbana. Cuando la Geografía ya tenía peso en la Universidad de Zaragoza, de acuerdo con el Rectorado, se obtuvo del Ministerio de Educación y Ciencia el visto bueno para la creación en nuestro Departamento de Geografía de una Cátedra de Geografía Urbana, cuya provisión se haría por el procedimiento ordinario, es decir, por oposición pública, pero financiada durante los cinco primeros años por instituciones públicas y privadas. No era solo una cátedra, sino que en el "paquete docente" se incluían dos profesores adjuntos del recién creado Cuerpo de Adjuntos de Universidad, como entonces se denominaba el primer escalón de Profesores Permanentes, y dos ayudantes. Todo ello con sus correspondientes dotaciones económicas para prácticas, material y salidas de campo. La fórmula no era nueva. La Facultad de Ciencias Económicas y la Escuela de Ingenieros se habían creado con la misma fórmula. El proyecto no llegó a término; podría parecer que la creación de una cátedra sería algo más fácil, pero no pudo ser.

Pero junto a estos "fracasos" hay muchos más logros. Fue fundactor de la revista Geographicalia, que todavía se edita después de un cuarto de siglo de andadura, y cuyo propósito era facilitar a los jóvenes geógrafos que se iniciaban en la investigación geográfica, la publicación de sus trabajos. Fue también el fundador de los Cursos de Geografía de Teruel que, bajo su dirección, se impartieron durante once años. A imitación de las universidades francesas, durante diez años organizó una "excursión universitaria" para profesores del Departamento (algunos años hubo dos excursiones, una para profesores y otra para alumnos) a la que se invitaba a algunos profesores de otras universidades, pensando siempre en la formación de los jóvenes geógrafos que entonces empezaban la carrera docente. Justificaba estos viajes diciendo que eran necesarios, porque si bien "la teoría se aprende en los libros, y por eso hay que leer mucho y reflexionar sobre lo que se lee,... la Geografía se aprende mejor en el campo".

Del profesor Higueras quedan muchas cosas por decir, algunas de las cuales ha prometido contarlas en sus "memorias". Ahora, para terminar, quiero anadir que, como aragonés y zaragozano de nacimiento, ha tenido una destacada vida pública subordinada siempre a su actividad universitaria. A lo largo de los años setenta y ochenta desempenó cargos de responsabilidad política y científica: en 1968, fue miembro suplente del Consejo Nacional de Educación. Más tarde miembro de la Junta Directiva del Patronato José Maria Cuadrado de Estudios Locales del C.S.I.C., de 1971 a 1981. Desde 1971 hasta 1979 fue Diputado Provincial de la Diputación Provincial de Zaragoza en representación de la Universidad, Diputado Delegado de Cultura en la Institución Fernando el Católico de la Diputación Provincial de Zaragoza y Director de la cátedra "Asso" de la misma Institución. Ha desempeñado el cargo de Vicedecano de la Facultad de Filosofía y Letras, Director del Servicio de Estudios Económicos de la Caja de Ahorros de Zaragoza desde 1973 hasta 1992 y Concejal del Ayuntamiento de Zaragoza de 1983 a 
1987. A lo largo de los últimos 36 años ha sido Director del Departamento de Geografía de la Universidad de la Zaragoza en muchas ocasiones, la última de 1998 a 1999, año en que dimite por haber alcanzado la edad reglamentaria de la jubilación.

Al profesor Higueras no sólo se le conoce en ambientes científicos españoles, sino que su proyección internacional es enorme. Las tempranas relaciones internacionales que desarrolló en los comienzos de su vida profesional se han mantenido y ampliado a lo largo del tiempo. Si bien mantiene estrechas relaciones con investigadores y centros universitarios de todo el mundo, éstas, por razones obvias, son mas frecuentes con las del entorno europeo, y muy especialmente, lo cual es ya más raro, con los antiguos países de Europa del Este, con los que muy pronto llegó a mantener intensos contactos científicos. En 1992, el Presidente polaco Walesa le impuso una alta condecoración por su labor en pro de las relaciones culturales entre España y Polonia. Ya en 1988 había sido nombrado Miembro Honoris Causa de la Sociedad Geográfica Polaca. Desde el curso 2000-2001 es Profesor Emérito de la Universidad de Zaragoza.

Zaragoza, Diciembre de 2002

\section{Relación de trabajos citados}

(1956): Ia geodemografía de la provincia de Logroño (1900-1950). Geographica, 9-12.

(1958): Estudio agrobiológico y mapa de suelos del valle del río Saja. Anales de Edafologia.

(1958): Mapa de suelos de la provincia de Santander. Reseña geográfica. Anales de Edafología.

(1958): Die Stellung der Bodenkunde in cier Geographischen Wissenschaft. Die Erde.

(1959): Sobre la fotografia aérea como instrumento de trabajo en Geografia. Geograpbica.

(1960): Micromorphologic and Chemical Study of Humus Formation from Different
Vegetal Species. En 7th International Congress of Soil Science. EE.UU., Madison (Wisconsin).

(1960): El clima del SE. de España. Estudios Geográficos.

(1961): El Alto Guadalquivir, estudio geográfico. Zaragoza, C.S.I.C e Instituto de Estudios Giennenses.

(1962): Influencia de la vegetación en los procesos de humificación de suelos forestales pirenaicos. ). En Actas Congreso Estudios Pirenaicos. Pau-Lourdes (en colaboración).

(1962): Los suelos naturales de las islas de Sta. Maria y San Miguel (Azores). Açoreana, vol. $V I, n^{\circ} .1$. 
(1964): La cartografía de suelos en España. En Actas del XX Congreso Geográfico Internacional. Reino Unido.

(1964):Los regadíos en España. En Actas de XX Congreso Geográfico Internacional. Reino Unido.

(1964): Estudio de los suelos en los nuevos regadios del Valle Medio del Ebro. (Proyecto de investigación inédito para la Fundación March.

(1964): El regadio en el Valle Medio del Ebro. Información Comercial Española.

(1965): Caracterización mineralógica y micromorfológica de algunos suelos calizos del Pirineo. Anales de Edafologia, vol. XXIV, $n^{\circ}$. 7-8 (en colaboración).

(1965): Motivos de la concentración urbana En Problemas de concentración urbana. Madrid, XXIV Semanas Sociales de España.

(1965): D. Eduardo Hernández Pacheco 18721965. Geographica.

(1966): El mapa de utilización del suelo según los datos del catastro. En Actas del III Coloquio de Geografia.

(1966): El consumo de frutas y verduras en Madrid. En Homenaje al Excmo. Sr.D. Amando Melón. Zaragoza.

(1967): Methoden und Einrichtungen der Herstellung von Boden Dünnschliffen in der Sektion für Micromorphometrische Boden Analyse. En Die mikromorphometrische Bodenanalyse. Stuttgart, Ferdinand Enke Verlag.

(1967): La emigración interior española. Madrid, Mundo del Trabajo.

(1967) Geopolitica y Geoestrategia. El concepto de Frontera en Geografia. Zaragoza,
Universidad de Zaragoza/Cátedra General Palafox.

(1968) Nota acerca del crecimiento de la población de Zaragoza 1960-67. En Miscelanea de bomenajeal Ilmo. Sr. D. J.M Lacarra. Zaragoza, Excma. Diputación Provincial.

(1969): Algunos aspectos de los desequilibrios regionales españoles en 1967. En Aportación Española al XXI Congreso Geográfico Internacional. Madrid (en colaboración).

(1969): La agricultura de regadío en España. En Suma de Estudios en Homenaje al Doctor Canellas. Zaragoza.

(1971): Estudio conjunto de los problemas comunes de las tres provincias aragonesas. Zaragoza, vol. XXXIII

(1971-1985): Atlas Regional de Aragón (inédito).

(1972): Nota acerca de la economía del regadío aragonés. Volumen En Homenaje a D. J. M. Casas Torres 1944-1969, veinticinco años de docencia universitaria. Zaragoza

(1973): Aragón, años setenta. Zaragoza, vol. XXXIX-XL.

(1974): Indices de evapotranspiración potencial del Valle Medio del Ebro. Zaragoza, Estación Experimental de Aula Dei (en colaboración).

(1975): Estructura demográfica de la provincia de Zaragoza. Estudios Geográficos, 138 139 (en colaboración)

(1975): La población del Valle Medio del Ebro. Distribución espacial y equipamientos. Zaragoza, Consejo Económico Sindical Interprovincial del Ebro (en colaboración). Zaragoza, 1975. 
(1976): "Las comarcas ante el desarrollo regional", Estudios Regionales.

(1978): "La población asalariada de Galicia". En Homenaje al Profesor Otero Pedrayo. Santiago de Compostela, Universidad de Santiago.

(1978): Nuevas tendencias de la Geografía. Revista Bachillerato. Madrid, Ministerio de Educación y Ciencia.

(1979): El sector agrario en Aragón. Zaragoza, Caja de Ahorros de Zaragoza, Aragón y Rioja.

(1981): El papel del geógrafo en las investigaciones sobre el espacio urbano. Geographicalia, 11-12.

(1981): Los desequilibrios regionales en España. Geograpbicalia.

(1981): Cuestiones de desarrollo regional. En Actas de la $V$ Reunión de Estudios Regionales. Zaragoza, Asociación Española de Ciencia Regional.

(1981): Cuentas regionales de la economía aragonesa. Zaragoza, Caja de Ahorros de Zaragoza, Aragón y Rioja.

(1981): Reflexiones acerca de los movimientos de población. Geographicalia, 9.

(1981-1983): Geografia de Aragón. Zaragoza, Guara editorial, 6 vol. (dirección de la obra).

(1983): Tablas input-ouput y cuentas regionales de la economía riojana. Zaragoza, Caja de Ahorros de Zaragoza, Aragón y Rioja.

(1986): Estructura y perspectivas demográficas de Aragón. Primera parte. Zaragoza, Caja de Ahorros de Zaragoza, Aragón y Rioja.
(1988): Estructura y perspectivas demográficas de Aragón. Segunda parte. Zaragoza, Caja de Ahorros de Zaragoza, Aragón y Rioja.

(1989): El espacio agrícola riojano. El Campo, Boletin de información agraria.

(1989) La ciudad como fenómeno ecológico. Geographicalia, 26.

(1989): New towns en Espagne. Acta Universitatis Lodziensis. Folia Geographica, 11 .

(1991): Les inegalités geographiques de la mortalité. Espaces, Populations, Sociétés, I.

(1991): Perspectivas demográficas de Aragón. Tercera parte: municipios. Provincia de Huesca. Zaragoza, Real Sociedad Económica Aragonesa de Amigos del País.

(1991): Perspectivas demográficas de Aragón. Tercera parte: municipios. Provincia de Zaragoza. Zaragoza, Real Sociedad Económica Aragonesa de Amigos del País.

(1991) Perspectivas demográficas de Aragón. Tercera parte: municipios. Provincia de Teruel. Zaragoza, Real Sociedad Económica Aragonesa de Amigos del País.

(1991): El envejecimiento de la población aragonesa. Papeles de Economía Española. Aragón.

(1991): Fertility and social change in Spain (1975-1987). En The geographical approach to fertility. Kiel, Kieler Geograph. Schrif.

(1991): Rural depopulation. Zaragoza, Unión Geográfica Internacional/ Comisión de Geografía de la Población.

(1991): Depopulation in rural áreas in Spain 1959-1985. En Rural Depopulation. Zaragoza, Unión Geográfica Internacional/Comisión de Geografía de la Población. 
(1994): The present situation in Spain regarding the transformation of arid land into irrigated land. En UNESCO/IUSSP/IGU, Conference on Population and Environnment in Arid Regions. Amman (Jordania).

(1995): Perspectivas demográficas de Aragón. En Actas III Congreso de Economía Aragonesa. Zaragoza, Universidad de Zaragoza.

(1996): El déficit demográfico de Aragón. E área de Monzón. CEHIMO Cuadernos, 23.

(1997): La población mundial hacia el tercer Milenio: Zaragoza, Universidad de Zaragoza.

(1997): Degradation environnemental causée par l'emigration et le vieillissement de la population dans les zones de montagne d'Aragon (Espagne). En Symposium International Population, Environnement et Pauvreté. Rabat, Centre D'Etudes et de Recherches Démographiques (CERED) y Unión Geográfica Internacional.

(1998): Two examples of environmental transformation in dry Spain. En Clarke, P. y Noin, D.,eds., Population and environment in arid regions. Paris, Unesco, MAB Man and the biosphere series, 19.

(1999): La Inmigración Extranjera en Aragón. En Migraçao, naçao, lugar e dinamicas territoriais. Sao Paulo, Brasil

(1999): Características de la población rural española. En El seu mestratge en la Geografia Universitaria (Homenaje al Dr. Joan Vilá Valentí). Barcelona, Universitat de Barcelona, Coll. Homenatges, $n^{\circ} 15$.

(2000): Does a demographic deficit exist? Applied Geography, 20.

(2000): Turismo, paisaje y medioambiente. Reflexiones geográficas. En Turismo en Cuba. Geographicalia (publicación no seriada).

(2002): Fronteras y globalización en Europa. Curitiba, Brasil.

(En prensa): Teoria método de la Geografía (Introducción al análisis geográfico regional. Zaragoza, Prensas Universitarias de la Universidad de Zaragoza. 